\title{
Anisotropic Dislocation Loop Distribution in Alloy T91 during Irradiation Creep
}

Cheng Xu, Gary S. Was

University of Michigan, 2355 Bonisteel Blvd, Ann Arbor, MI 48109-2104, USA

\begin{abstract}
Ferritic-martensitic (FM) steel $T 91$ was subjected to irradiation with $3 \mathrm{MeV}$ protons while under load at stresses of 100MPa, 180MPa, and 200MPa. Transmission electron microscopy of crept T91 samples was conducted to determine the nature of the loops and to quantify the edge-on dislocation loop density as a function of their orientation to the tensile axis. Loops were determined to be interstitial in nature of the type $a_{o}\langle 100\rangle$. The distribution of $a_{o}<100>$ loops was found to be strongly anisotropic in which loops preferentially formed with their normal in the tensile direction. An empirical correlation was developed to describe the relationship between the orientation of the loop normal to the tensile axis and the local dislocation loop density. Loop anisotropy was found to increase as a function of the applied stress and their strain contributions relative to total creep strain were calculated at 4-11\% of the total creep strain. Results from this study provide a means for quantifying empirically measured anisotropic microstructure and including it in irradiation creep mechanisms for FM steels.
\end{abstract}

Keywords:

Creep, dislocation loops, irradiation, ferritic martensitic steels, T91, anisotropy.

Corresponding author: Cheng $\mathrm{Xu}$

University of Michigan

2355 Bonisteel Blvd, Ann Arbor

MI, 48109-2104
Phone: 7346213647

Email: chengxu@umich.edu

C 2014. This manuscript version is made available under the Elsevier user license http://www.elsevier.com/open-access/userlicense/1.0/ 


\section{Introduction}

Interstitial loops have been theorized to play an important role in the irradiation creep of nuclear materials. Loops can only contribute to creep if their orientations are anisotropic such that more are oriented with their habit planes normal to the applied stress than parallel to it. Hesketh et al. [1] first proposed the link between dislocation loops and irradiation creep in uranium. Lewthwaite et al. [2] extended the mechanism to austenitic steels where irradiation induced vacancies cluster to form voids that drive swelling, while interstitials cluster to form loops that drive irradiation creep. Herschbach et al. [3] further developed a method to calculate the strain contribution from dislocation loops while taking into account both the effect of irradiation and applied stress. However, the calculation of the loop contributions up to that point were based on the assumption that the dislocation loop density anisotropy would be proportional to a Boltzmann factor, where the external applied stress modified the loop nucleation energy in the exponential term of the expression for dislocation loop concentration [4]. The validity of the assumptions for loop anisotropy calculations have been debated and challenged [4-6].

Direct measurement of anisotropy in the dislocation loop density was first conducted by Okamoto et al. [7] in solution annealed (SA) 316 stainless steel irradiated in EBRII at $410^{\circ} \mathrm{C}$ and $207 \mathrm{MPa}\left(30 \mathrm{ksi}\right.$ ) hoop stress to a total fluence of $2.4 \times 10^{21} \mathrm{n} / \mathrm{cm}^{2}$. Four distinct loop orientations, [-1-11], [111], [-111], [1-11], were imaged under bright field and dark field conditions. It was found that the four loop orientations all had the same loop size within 5\%. However, the loop concentration on different sets of $\{111\}$ planes varied by as much as a factor of two. Okamoto et al. [7] concluded that the observations supported the stress-biased loop nucleation mechanism, where loops 
nucleated on preferred $\{111\}$ planes, as playing a significant role in the irradiation creep of SA 316 stainless steels.

The effect of stress on dislocation loop microstructure of 316 stainless steel in both SA and $20 \%$ cold worked state were examined by Brager et al. [8]. Pressurized tube specimens of stainless steel were irradiated in EBRII to $3.0 \times 10^{22} \mathrm{n} / \mathrm{cm}^{2}$ at $500^{\circ} \mathrm{C}$ and hoop stress as high as $327 \mathrm{MPa}$. Loop number density measurements showed that, for a given Hoop stress condition, there was a clear preferential nucleation of loops on planes with a higher resolved normal stress. For the $20 \%$ coldworked 316 stainless steel, doubling the resolved normal stress (200MPa vs. 100MPa) doubled the measured loop density in the same sample. The conclusion for irradiated austenitic steels was that a higher resolved normal stress primarily enhanced the nucleation of dislocation loops, with a secondary effect of increasing the size of the defects.

Gelles et al. [9] confirmed the anisotropy of loops in $20 \%$ cold worked 316 stainless steel by conducting transmission electron microscopy (TEM) analysis on pressurized tubes irradiated in FFTF to $8.0 \times 10^{22} \mathrm{n} / \mathrm{cm}^{2}$ at $450^{\circ} \mathrm{C}$ and a hoop stress of $138 \mathrm{MPa}$, and at $650^{\circ} \mathrm{C}$ with a hoop stress of $69 \mathrm{MPa}$. It was observed that one set of $<111>$ loops had a much higher number density compared to another set of <111> loops in the same sample, depending on the Burgers vector orientation. The ratio of number densities of the loop sets was described as the anisotropy factor. The anisotropy factor of the loop Burgers vector was reported to be 4.3 to 5.3 for these samples. In addition, Gelles et al. [9] also documented the anisotropy found in a duplex ferritic/martensitic alloy irradiated in FFTF at $407-520^{\circ} \mathrm{C}$ to $7.5 \times 10^{22} \mathrm{n} / \mathrm{cm}^{2}$ with a stress up to $90 \mathrm{MPa}$. The anisotropy factor for different orientations was reported to be as large as 7.3 for $\mathrm{a}_{\mathrm{o}} / 2<111>$ loops and up to 2.7 
for $\mathrm{a}_{0}<100>$ loops. However, the analysis on the duplex steel was only done on the deltaferrite regions and not the martensitic regions. Therefore, observations of dislocation loop anisotropy in tempered martensitic steels have yet to be documented.

A recent detailed TEM analysis of ferritic RAFM steel irradiated to 3.9dpa in HFIR confirmed the previous results of anisotropy in the $a_{o}<100>$ dislocation loop density [10]. This study confirmed that at temperatures above $400^{\circ} \mathrm{C}$, the ferritic RAFM steel is dominated by $a_{o}<100>$ sessile dislocation loops rather than $a_{0} / 2<111>$ glissile loops. The ratio of the sessile loops with different orientations relative to glissile loops was reported to be as much as a factor of 5. The paper differentiated the anisotropy between the two loop types but made no attempt to quantify the relationship between the loop anisotropy to the applied stress.

Many studies have been conducted in an attempt to understand the anisotropy in the dislocation loop density and its impact on irradiation creep mechanisms. The classic interpretation of the loop density anisotropy due to stress induced preferential nucleation (SIPN) is not a satisfactory explanation for irradiation creep on the grounds that interstitial emission is not energetically favorable in bcc steels. The lack of a loop dissolution mechanism makes SIPN incompatible with traditional nucleation theory where a steady state loop concentration will eventually be achieved. Additional theories were proposed to reconcile the observation of anisotropic dislocation loops with known irradiation creep mechanisms. [6] It was suggested that preferential absorption of vacancies can occur in addition to preferential nucleation of interstitials that allows for the loop density to reach steady state. This mechanism was described as stress induced 
preferential absorption (SIPA), and the absorption of vacancies predicts anisotropy in the dislocation diameter as a function of their orientation to the tensile axis.

Determining whether an anisotropic dislocation loop microstructure contributes to irradiation creep requires a systematic method to quantify the anisotropy observed from experiments. However, a standardized measurement or analysis technique of anisotropy has not yet been established. Investigators often report an anisotropy factor based solely on observations of specific sets of dislocation loop density without taking into consideration the complex interdependent relationship between the external stress, grain orientation, and loop plane orientation. Although empirical observations on 316 stainless steel have consistently confirmed the existence of dislocation loop anisotropy, the magnitude of the anisotropy and its relationship with the applied stress are still not immediately clear for FM steels.

This study seeks to establish a direct link between the dislocation loop microstructure and the applied tensile stress in FM steel T91. Low dose proton irradiation creep experiments were conducted in the Michigan Ion Beam Laboratory (MIBL), and the irradiated samples were analyzed at the Electron Microbeam Analysis Laboratory (EMAL) at the University of Michigan, and the Nanotech User Facility (NTUF), at University of Washington. The nature of the loops observed and the anisotropy of the $a_{o}$ $<100>$ dislocation loop density and loop size were described as a function of the loop orientation relative to the tensile stress. The results of the microstructure analysis are discussed along with its implications for existing irradiation creep theories.

\section{Experimental}


The composition of the T91 heat used in this experiment is given in Table 1. The as-received T91 plate was normalized at $1040^{\circ} \mathrm{C}$ for 46 minutes, followed by air cooling, then tempering at $760^{\circ} \mathrm{C}$ for 42 minutes. The samples were made by electric discharge machining into a dog-bone shape with a thickness of $100 \mu \mathrm{m}$, as shown in Figure 1. The samples were electro-polished in a $10 \%$ percholoric acid, and $90 \%$ methanol solution at $40^{\circ} \mathrm{C}$. An applied voltage of $20 \mathrm{~V}$ produced a current density of $2 \mathrm{~A} / \mathrm{cm}^{2}$. The average removal rate of this electro-polishing method was $20 \mu \mathrm{m} / \mathrm{min}$, and the samples were polished to a final thickness of $35 \underline{ \pm} 2 \mu \mathrm{m}$.

Irradiation creep experiments were conducted in a specially made irradiation creep stage described extensively in a previous paper by $\mathrm{Xu}$ and Was [11]. Irradiations were conducted using $3 \mathrm{MeV}$, which have a penetration distance of $40 \mu \mathrm{m}$ in stainless steel, to ensure that there is no implantation within the $35 \mu \mathrm{m}$ sample. The experimental setup, shown in Figure 2, has the capability for in-situ strain measurements for a dogbone sample under uniaxial tensile stress, high temperature, and proton irradiation. For this study, four irradiation creep experiments were conducted at either $450^{\circ} \mathrm{C}$ or $500^{\circ} \mathrm{C}$, at dose rates between $3.4 \times 10^{-6}$ and $1 \times 10^{-5} \mathrm{dpa} / \mathrm{s}$ to doses of 1-2 dpa and under loads of 100 - $200 \mathrm{MPa}$. Microstructure of the crept samples were analyzed using TEM. Two temperatures, two doses, and three stress conditions were explored across the four samples to create the experimental matrix outlined in Table 2. Sample designation IT450100 denotes a T91 sample subjected to irradiation creep at $450^{\circ} \mathrm{C}$ and $100 \mathrm{MPa}$ applied stress.

Microstructure analysis of the irradiation creep samples was conducted using TEM at specific conditions to obtain information on the orientation of dislocation loops. 
The TEM samples were made using focused ion beam (FIB) milling to lift out a sample that preserved the tensile axis orientation as shown in Figure 1. The TEM samples were imaged in the $<001>$ zone axis under a two beam condition with $g=\langle 110\rangle$ such that two sets of edge-on $\mathrm{a}_{0}<100>$ loops were visible. The angle $\theta$ between the normal vector of the dislocation loop plane and the tensile axis was used to define the loop orientation as shown in Figure 3. The number of dislocation loops and the diameter of the two sets of edge-on loops were measured as a function of the loop orientation to the tensile axis. This analysis provides an empirical stress dependence for the anisotropy of dislocation loop density in FM steels, removing the reliance on theoretical assumptions for the calculation of strain contribution from dislocation loops [3-5].

\section{Results}

Four experiments were conducted at distinct temperatures, stresses, and dose rates to characterize the anisotropy in the microstructure of FM steel T91 after irradiation creep. Microstructure analysis of the irradiation creep samples showed clear signs of loop anisotropy as a function of applied stress. Figure 4 shows a typical TEM image of the four irradiation creep samples as imaged in the $\langle 001\rangle$ zone axis with $g=\langle 110\rangle$. Each grain imaged had two sets of edge-on loops (one set consisting of $a_{0}[100]$ and $a_{0}[-100]$ loop, and the other set consisting of $\mathrm{a}_{\mathrm{o}}[010]$ and $\mathrm{a}_{\mathrm{o}}[0-10]$ loops). Each set of loops had a unique angle between the loop plane normal vectors and the tensile axis. The number of loops in each set were counted and diameter measured as a function of their orientation to the tensile axis. Other microstructure features such as voids and sub-grain structure were also analyzed. 


\subsection{Dislocation Loop Anisotropy}

The total number of loops within each grain can vary depending on the size of the grain imaged. In order to make appropriate comparisons between the loop densities from different grains, the loop number density for each orientation of $\mathrm{a}_{\mathrm{o}}<100>$ loops was normalized by the total number of $a_{0}<100>$ loops in that grain. The anisotropy in the loop density was defined by the fraction of one set of $a_{o}<100>$ loops over the entire $a_{0}<100>$ loop population of that grain. This normalized dislocation loop density is plotted against angle $\theta$ for all samples in Figure 5. The average loop diameter of a set of loops is shown in red, and the normalized loop density is shown in blue. The measurements showed that the dislocation loop diameter did not depend on the angle between the loop plane normal and the tensile axis.

In contrast, Figure 5 shows a strong dependence of the dislocation loop density on the angle between the loop plane normal and the tensile axis, as shown by the blue line fits in Figure 5. The relationship between the loop plane normal, the tensile axis and local dislocation loop density was described by the simple inverse linear relationship given by:

$$
\frac{N(\theta)}{N}=\alpha-\beta \theta
$$

where the constants $\alpha$, and $\beta$ are fitting constants, and $\theta$ is defined as the angle between the loop normal and the tensile axis as shown in Figure 3. $N$ is the total loops in the grain, and $N(\theta)$ is the loop number density for a set of loops with angle $\theta$ to the tensile axis. The left hand side of the equation describes the anisotropy of loops in a given irradiation creep sample. The anisotropy becomes larger as the externally applied stress increases at a constant temperature and dose rate, which is reflected by the larger slope with 
increasing stress in Figure 5. The slope of the line $(\alpha)$ indicates the strength of the anisotropy, and the values are tabulated in Table 3.

The anisotropy in the four different irradiation creep samples can be compared directly by calculating the resolved normal stress on each set of loops observed. The resolved normal stress is defined as the component of the applied stress that is acting normal to the dislocation loop plane. This value was obtained by taking the projection of the tensile stress vector to the loop normal vector. The magnitude of the resolved normal stress was calculated by multiplying the magnitude of the uniaxial tensile stress by $\cos ^{2}(\theta)$. Brager et al. [8] conducted a similar analysis for $<111>$ loops in $20 \%$ cold worked 316 stainless steel. It was determined that preferred planes within a sample that has higher resolved normal stress will have a higher dislocation loop density. A plane subjected to resolved normal stress of $200 \mathrm{MPa}$ had a loop density of $9 \times 10^{14} \mathrm{loops} / \mathrm{cm}^{3}$, doubling the $4 \times 10^{14}$ loops $/ \mathrm{cm}^{3}$ observed on planes with $100 \mathrm{MPa}$ resolved normal stress. Figure 6 plots the anisotropy of the $a_{0}<100>$ loops observed in this study as a function of the resolved normal stress on the loops. The results show a similar trend to that of Brager et al. [8]. Preferred loop nucleation in this experiment was demonstrated by the increase of $\mathrm{a}_{\mathrm{o}}<100>$ loop density on planes with increasing the resolved normal stress, for the same applied stress on the sample.

While the angle of the loop plane to the tensile axis did not affect the loop diameter, the tensile stress did. The loop size distributions are plotted in Figure 7, where the average loop diameter of $42.3 \mathrm{~nm}$ for the $200 \mathrm{MPa}$ condition was significantly higher than that at lower stress. Meanwhile, there was also no measurable effect of temperature on loop diameter between $450^{\circ} \mathrm{C}$ and $500^{\circ} \mathrm{C}$ conditions. 


\subsection{Dislocation Loop Nature}

Dislocation loops in FM steels have traditionally been assumed to be interstitial in nature. Experimental observations of neutron irradiated FM steel HT-9 duct in FFTF revealed glissile $a_{0} / 2<111>$ and sessile $a_{o}<100>$ interstitial loops following irradiation [12]. These observations were consistent with other irradiation studies on FM steels HT9, EM10, MANET and T91 [13], [14]. Molecular dynamic simulations on bcc crystals suggested that $a_{0} / 2<111>$ dislocation loops grew out of $<111>$ dumbbell SIA defect clusters. The $\mathrm{a}_{\mathrm{o}} / 2<111>$ glissile loops then interacted to form $\mathrm{a}_{\mathrm{o}}<100>$ sessile loops [15]. An analysis of dislocation loops was also conducted in this study to empirically determine their nature; vacancy or interstitial. Figures 8 and 9 show the results of $a_{0}[100]$ and $\mathrm{a}_{\mathrm{o}}[010]$ type dislocation loops imaged on the [001] zone axis. Each dislocation loop was imaged under a two-beam condition with both positive and negative g vectors. Figure 8 shows that with $g=[020]$, the loop with $b=[010]$ had outside contrast, and with $g=[0-20]$, it had inside contrast. Figure 9 shows that when $g=[1-10]$, the loop with $b=[100]$ had outside contrast, and with $\mathrm{g}=[-110]$, it had inside contrast. In both cases, the outside contrast was observed when $\mathrm{g}$ is positive, suggesting that these loops were interstitial in nature. Although this analysis was done on a large $\mathrm{a}_{0}<100>$ loop, it was assumed that all $a_{0}<100>$ loops are of interstitial nature. The findings were consistent with conclusions from neutron irradiated FM steels. [16], [17]

\subsection{Other Microstructures}


In addition, grain size, dislocation line density, and voids were also analyzed in sample IT450200, and compared to an unstressed irradiated sample IT450000, and a thermal creep sample TT450200. In all three cases, no voids were identified, most likely due to the low dose irradiation conditions. The sub-grain sizes were all very similar at around $0.5 \mu \mathrm{m}$ in diameter, and dislocation line densities were also similar at around $4 \times 10^{14} \mathrm{~m}^{-2}$. Dislocation loops were the microstructure feature that differed significantly from the unirradiated and unstressed conditions and will be the focus of the discussion of this paper.

\section{Discussion}

Several key observations on the irradiation creep microstructure of FM steel T91 were made as the result of this study. First, anisotropy in the dislocation loop density was observed. Second, anisotropy in the dislocation loop diameter was not observed. Lastly, the effects of temperature, stress and dose rate on the dislocation loop microstructure were analyzed and will be discussed.

\subsection{Dislocation Loop Density Anisotropy}

An anisotropic distribution of $\mathrm{a}_{0}<100>$ interstitial dislocation loops described in this study disproportionally stacks more atoms in the tensile direction since more interstitial loops nucleate on planes perpendicular to the tensile axis. This anisotropy can cause strain in the tensile direction due to the extra half planes orienting preferentially to the tensile axis. 
Kroupa et al. [18] defined the strain in a volume due to a continuous distribution of dislocation loops as the following strain tensor:

$$
\epsilon_{i j}=\sum_{k=1}^{N} \frac{S^{(k)} A^{(k)} n_{i}^{(k)} b_{j}^{(k)}}{\Delta V}
$$

The equation describes the strain $\varepsilon$ caused by $N$ groups of loops in a volume $\Delta V$, where the $k^{\text {th }}$ group of loops all have the same Burgers vector $b$, area $A$, normal vector $n$ and number density $S$. The subscript $i$ denotes $\mathrm{x}, \mathrm{y}, \mathrm{z}$ directions of the loop normal vector, and subscript $j$ denotes the contribution of loop Burgers vectors to the $\mathrm{x}, \mathrm{y}, \mathrm{z}$ directions.

Each variable was measured in this study, yielding the following expression for a single group of loops in a single grain:

$$
\epsilon_{i j}^{(k)}=\frac{N^{(k)} \pi\left(\frac{D}{2}\right)^{2} n_{i}^{(k)} b_{j}^{(k)}}{\Delta V}
$$

where $N^{(k)}$ is the total number of the $k^{\text {th }}$ loop in the volume $\Delta V . D$ is the measured loop diameter. Because only $a_{0}<100>$ type loops were analyzed, the subscript on the Burgers vector can be dropped. Analysis of the anisotropy of the dislocation loops determined that $N^{(k)} / N=\alpha-\beta \theta^{(k)}$ as described by eqn. (1). Let the bulk dislocation loop density, $\rho$, be defined as $N / \Delta V$, and eqn (3) becomes:

$$
\epsilon_{i}^{(k)}=b \rho \pi\left(\frac{D}{2}\right)^{2} n_{i}^{(k)}\left(\alpha-\beta \theta^{(k)}\right)
$$

If we define the coordinate axis such that the tensile axis is in the z-direction as shown in Figure 10, then the loop normal vector, $n$ is defined by the following:

$$
n^{(k)}=\left[\begin{array}{c}
x \\
y \\
z
\end{array}\right]=\left[\begin{array}{c}
\sin \left(\theta^{(k)}\right) \cos \left(\phi^{(k)}\right) \\
\sin \left(\theta^{(k)}\right) \sin \left(\phi^{(k)}\right) \\
\cos \left(\theta^{(k)}\right)
\end{array}\right] \text {, }
$$


where the angle $\theta^{(k)}$ is the angle between the normal vector of the $\mathrm{k}^{\text {th }}$ loop and the tensile axis, and $\phi^{(k)}$ is the azimuthal angle. Combining eqns (3)-(5), the strain vector $\varepsilon$ becomes only a function of the angles $\theta^{(k)}$ and $\phi^{(k)}$. The bulk strain can be determined by integrating over angles $\theta^{(k)}$ and $\phi^{(k)}$ :

$$
\epsilon_{i}=b \rho \pi\left(\frac{D}{2}\right)^{2} \frac{1}{C} \int_{\phi=0}^{\pi / 2} \int_{\theta=0}^{\pi / 2} n_{i}(\alpha-\beta \theta) d \phi d \theta .
$$

To avoid double counting the total number of loops when integrating across the angles, the integral is normalized by a constant $C$ such that the sum of the densities of each set of loops with any normal vector, $n$ becomes equal to the total loop density, $\rho$. The normalization constant $C$ is defined as follows:

$$
C=\int_{\phi=0}^{\pi / 2} \int_{\theta=0}^{\pi / 2}(\alpha-\beta \theta) d \phi d \theta
$$

Because the analysis by Kroupa et al. [18] assumed the loops were additional to the atoms in the matrix, the strains in all three directions were positive. The positive strains caused a volumetric expansion equal to the following:

$$
\epsilon_{v o l}=\epsilon_{x}+\epsilon_{y}+\epsilon_{z}
$$

This assumption violated the volume conservation of creep. In reality, the atoms that made up the dislocation loops originated from the matrix. For the purpose of this analysis, the atoms were assumed to originate equally from each of the $\mathrm{x}, \mathrm{y}$, and $\mathrm{z}$ directions. Therefore, one third of the volumetric expansion from dislocation loops was subtracted from the strain of the three primary directions. The assumption for volume conservation was chosen due to lack of observable voids in the samples, and lack of empirical measurements of volumetric expansion in this study. 
The final volume conservative strain calculated from the anisotropy of the loops becomes:

$$
\varepsilon_{i}=b \rho \pi\left(\frac{D}{2}\right)^{2} \frac{1}{C} \int_{\phi=0}^{\pi / 2} \int_{\theta=0}^{\pi / 2} n_{i}(\alpha-\beta \theta) d \phi d \theta-\frac{1}{3} \epsilon_{v o l}
$$

This integral was evaluated numerically using a Matlab® code developed at University of Michigan and provided in the Appendix. The result of the calculations for the samples IT450200, IT450180, IT450100, and IT500180 are plotted in Figure 11. The total strain due to the anisotropy of the loops is compared to the total measured strain in the sample in Table 4.

The strain due to anisotropy of the dislocation loops observed in the samples was found to account for only $4-11 \%$ of the total strain measured in the samples. This observation was consistent with previous works that claimed strain due to anisotropy in the dislocation loops was much lower than the total measured strain [6], and suggesting that another deformation mechanism must be driving the irradiation creep behavior.

\subsection{Dislocation Loop Diameter Anisotropy}

No anisotropy in the diameter was observed in the $\mathrm{a}_{\mathrm{o}}<100>$ dislocation loops, since there was no observable trend between the dislocation loop diameter and the angle of its loop normal to the tensile axis. The average loop diameter and size distribution were similar between the IT450100, IT450180, and IT500180 samples with different temperature, stress, and dose rate conditions. The IT450200 sample was the only exception with a much higher population of larger dislocation loops compared to those of lower stress. This result indicates that a higher tensile stress may be increasing the loop diameter, even if differences in resolved shear stress do not have an effect. 
The lack of anisotropy in the dislocation loop size has often been taken as evidence against anisotropic diffusion of point defects due to the stress field, since preferential absorption predicts anisotropic loop growth. [19] However, observation of large dislocation loops at high stress indicated that an external stress can affect the dislocation loop microstructure in a less direct manner. Gelles et al. [9] and Wolfer et al. [4] have both discussed the possibility of dislocation loops growing and interacting with dislocation networks under the influence of stress-induced anisotropic absorption of defects. STEM analysis in this study provided qualitative evidence of such interactions shown in Figure 12. Although no anisotropy in the dislocation loop size was observed in this study, it is still possible that stress-induced preferential absorption (SIPA) is occurring during irradiation creep. Woo et al [20], [21] further expanded on the SIPA mechanism to include the climb of anisotropic dislocation network as a deformation mechanism; therefore, the microstructural evidence relating the dislocation loop size to stress could be hidden by the interactions of large dislocation loops and the dislocation network.

\subsection{Parameter Dependence of Dislocation Loops}

The effect of stress on the dislocation loop density was demonstrated by $a_{0}<100>$ dislocation loops exhibiting anisotropic nucleation behavior. The anisotropy in loop nucleation was described by a linear relationship between the normalized loop density and the angle of the loop normal to the tensile axis. The magnitude of the anisotropy itself was also found to be affected by stress, as the slope ( $\alpha$ ) became larger as the applied stress was increased at a constant temperature and dose rate shown in Figure 5. 
Comparison at constant temperature and dose rate between the 180MPa and 200MPa conditions (IT450180 and IT450200) showed that increasing stress could also increase the dislocation loop diameter, but that observation was not supported by the dislocation loop size observed at 100MPa. However, the dislocation loop diameter at 100MPa could be larger due to the higher total dose instead of the applied stress.

Direct comparison between the samples irradiated at the same dose and stress (IT450180 and IT500180) showed that a combination of higher temperature and dose rate increased the loop anisotropy in the sample, but had no effect on the dislocation loop diameter. If dislocation loop nucleation growth was governed by basic diffusion kinetics, then an increase in temperature should increase the dislocation loop diameter and reduce the dislocation loop density due to a lower steady state point defect concentration. However, the observations of loop microstructure did not support these predictions. The lack of difference in the dislocation loop diameter between the two samples suggested that temperature was not a major factor in dislocation loop evolution, and the higher anisotropy for IT500180 was mainly due to the higher dose rate influencing loop nucleation. The observations of loop microstructure dependence on stress, temperature, and dose rate suggest that loop anisotropy was mainly driven by the applied stress and radiation damage.

This study provided the means for quantitative analysis of the stain due to the anisotropic dislocation loop distribution. The strain due to the loop anisotropy was calculated based on empirical microstructural evidence instead of theoretical assumptions. The result of the analysis indicated that anisotropy in the dislocation loops alone could not account for the total irradiation creep strain measured in the sample. However, this 
method allows future studies to include the effect of loop anisotropy of FM steels in the calculations of other creep mechanisms, such as stress induced preferential absorption (SIPA) and preferential absorption glide (PAG) mechanism proposed by Mansur et al [22]. Inclusion of the effect of an anisotropic microstructure may improve the accuracy of existing irradiation creep theories.

\section{Conclusion}

Four irradiation creep experiments were conducted at various temperature and stress conditions to low dose. Anisotropy in the resulting dislocation loop density was observed for all irradiation creep samples, with greater applied stress inducing a greater level of anisotropy. No significant temperature dependence was observed in the dislocation loop anisotropy, consistent with irradiation creep theory. The strain due to the loop anisotropy accounted for $4-11 \%$ of the total creep strain. The dislocation loop diameter was shown to have no anisotropy, but a high external stress increased the average loop diameter. Results of this study provide a basis for quantitative calculations of anisotropy effects in irradiation creep based on observable microstructure features for FM steel T91.

\section{Acknowledgements}

The authors gratefully acknowledge Ovidiu Toader and Fabian Naab for their assistance in conducting proton irradiations, and Lumin Wang, Kai Sun and Scott Braswell for their assistance in TEM analysis. Micah Hackett for his helpful discussion and insights. The authors also acknowledge the facilities provided by the Michigan Ion Beam Laboratory, the Electron Microbeam Analysis Laboratory at University of Michigan, and Nanotech User Facility at University of Washington. Support for this 
research was provided by the Department of Energy under award NERI 08-055 DE-

FG07-07ID14894.

\section{References}

[1] R. V. Hesketh, "A Possible Mechanism of Irradiation Creep and its Reference to Uranium,” Philos. Mag., vol. 7, 1962.

[2] G. W. Lewthwaite and K. J. Proctor, "Irradiation-creep in a materials testing reactor,” J. Nucl. Mater., vol. 46, no. 1, 1973.

[3] K. Herschbach and W. Schneider, "INTERCONNECTION BETWEEN IRRADIATION CREEP AND INTERSTITIAL LOOP FORMATION IN fcc METALS," J. Nucl. Mater., vol. 51, pp. 215-220, 1974.

[4] W. G. Wolfer, "Correlation of radiation creep theory with experimental evidence," J. Nucl. Mater., vol. 90, pp. 175-192, 1980.

[5] G. W. Lewthwaite, "Interconnection between irradiation creep and interstitial loop formation in fcc metals," J. Nucl. Mater., vol. 54, no. 1, 1974.

[6] J. . Matthews and M. . Finnis, "IRRADIATION CREEP MODELS - AN OVERVIEW,” J. Nucl. Mater., vol. 159, pp. 257-285, 1988.

[7] P. R. Okamoto and S. D. Harkness, "STRESS-BIASED LOOP NUCLEATION IN IRRADIATED TYPE 316 STAINLESS STEEL," J. Nucl. Mater., vol. 48, pp. 204-206, 1973.

[8] H. R. Brager, F. A. Garner, and G. L. Gutherie, "The Effect of Stress on the Microstructure of Neutron Irradiated Type 316 Stainless Steels," J. Nucl. Mater., vol. 66, pp. 301-321, 1977.

[9] D. S. Gelles, "Effects of stress on microstructural evolution during irradiation.," J. Nucl. Mater., vol. 5, pp. 146-161, 1993.

[10] B. Yao, D. J. Edwards, and R. J. Kurtz, "TEM characterization of dislocation loops in irradiated bcc Fe-based steels," J. Nucl. Mater., vol. 434, no. 1-3, pp. 402-410, Mar. 2013.

[11] C. Xu and G. S. Was, "In situ proton irradiation creep of ferritic-martensitic steel T91," J. Nucl. Mater., vol. 441, no. 1-3, pp. 681-687, 2013. 
[12] B. H. Sencer, J. R. Kennedy, J. I. Cole, S. a. Maloy, and F. a. Garner, "Microstructural analysis of an HT9 fuel assembly duct irradiated in FFTF to 155dpa at $443^{\circ}$ C," J. Nucl. Mater., vol. 393, no. 2, pp. 235-241, Sep. 2009.

[13] E. A. Little, "Microstructural evolution in irradiated transitions to high dose behaviour steels :," vol. 206, pp. 324-334, 1993.

[14] G. Gupta, G. S. Was, and Z. J. Jiao, "Microstructural Evolution of Proton Irradiated T91,” J. Nucl. Mater., vol. 351, pp. 162-173, 2006.

[15] J. Marian, B. D. Wirth, R. Schaublin, J. . Perlado, and T. D. de la Rubia, "<100>Loop characterization in alpha iron: comparison between experiments and modeling," J. Nucl. Mater., vol. 307-311, pp. 871-875, 2002.

[16] R. Schaeublin, D. Gelles, and M. Victoria, "Microstructure of irradiated ferritic/martensitic steels in relation to mechanical properties," J. Nucl. Mater., vol. 307-311, pp. 197-202, Dec. 2002.

[17] B. H. Sencer, "Microstructural Stability of an HT-9 Fuel Assembly Duct Irradiated in FFTF," J. Nucl. Mater., vol. 414, pp. 237-242, 2011.

[18] K. Kroupa, "Dislocation Loops," in Theory of Crystal Defects - Proceedings of the Summer School held in Hrazany in September 1964, 1966, pp. 308-313.

[19] C. H. Woo and F. A. Garner, "A SIPA-based theory of irradiation creep in the low swelling rate regime," J. Nucl. Mater., vol. 194, pp. 1309-1312, 1992.

[20] C. H. Woo, "Irradiation creep due to climb-induced glide in an anisotropic dislocation structure," vol. 98, pp. 295-305, 1981.

[21] C. H. Woo, "EFFECTS OF AN ANISOTROPIC DISLOCATION STRUCTURE ON IRRADIATION DUE TO SIPA,” J. Nucl. Mater., vol. 80, pp. 132-143, 1979.

[22] L. K. Mansur, "Irradiation creep by climb-enabled glide of dislocations resulting from preferred absorption of point defects," Philos. Mag., vol. 39, p. 497, 1979. 
Table 1. Percent weight composition of T91

\begin{tabular}{|c|c|c|c|c|c|c|c|}
\hline & $\mathrm{Cr}$ & $\mathrm{Mo}$ & $\mathrm{Mn}$ & $\mathrm{Si}$ & $\mathrm{V}$ & $\mathrm{Ni}$ & $\mathrm{Cu}$ \\
\hline $\mathrm{Wt} \%$ & 8.37 & 0.9 & 0.45 & 0.28 & 0.22 & 0.21 & 0.17 \\
\hline $\mathrm{At} \%$ & 8.89 & 0.52 & 0.45 & 0.55 & 0.23 & 0.20 & 0.15 \\
\hline & $\mathrm{C}$ & $\mathrm{Nb}$ & $\mathrm{Al}$ & $\mathrm{N}$ & $\mathrm{P}$ & $\mathrm{S}$ & $\mathrm{Fe}$ \\
\hline $\mathrm{Wt} \%$ & 0.1 & 0.076 & 0.022 & 0.048 & 0.009 & 0.003 & $\mathrm{Bal}$ \\
\hline $\mathrm{At} \%$ & 0.05 & 0.045 & 0.045 & 0.189 & 0.016 & 0.005 & $\mathrm{Bal}$ \\
\hline
\end{tabular}

Table 2. Irradiation creep conditions for T91 experiments

\begin{tabular}{|c|c|c|c|c|c|}
\hline $\begin{array}{c}\text { Sample } \\
\text { Name }\end{array}$ & $\begin{array}{c}\text { Dose } \\
(\mathrm{dpa})\end{array}$ & $\begin{array}{c}\text { Dose Rate } \\
(\mathrm{dpa} / \mathrm{s})\end{array}$ & $\begin{array}{c}\text { Temperature } \\
\left({ }^{\circ} \mathrm{C}\right)\end{array}$ & $\begin{array}{c}\text { Applied Stress } \\
(\mathrm{MPa})\end{array}$ & $\begin{array}{c}\text { Irradiation Time } \\
(\mathrm{hr})\end{array}$ \\
\hline IT450100 & $\sim 2$ & $3.4 \times 10^{-6}$ & 450 & 100 & 170 \\
\hline IT500180 & $\sim 1$ & $1 \times 10^{-5}$ & 500 & 180 & 30 \\
\hline IT450180 & $\sim 1$ & $3.4 \times 10^{-6}$ & 450 & 180 & 80 \\
\hline IT450200 & $\sim 1$ & $3.4 \times 10^{-6}$ & 450 & 200 & 80 \\
\hline
\end{tabular}

Table 3. Characterization of loops in irradiation creep samples

\begin{tabular}{|c|c|c|c|c|c|}
\hline \multirow{2}{*}{$\begin{array}{c}\text { Sample } \\
\text { Name }\end{array}$} & $\begin{array}{c}\text { Number of } \\
\text { Loops Analyzed }\end{array}$ & $\begin{array}{c}\text { Average } \\
\text { Loop Size } \\
(\mathrm{nm})\end{array}$ & $\begin{array}{c}\text { Dislocation } \\
\text { Loop } \\
\text { Density }\left(\mathrm{m}^{-3}\right)\end{array}$ & \multicolumn{2}{|c|}{$\begin{array}{c}\text { Constants for Loop } \\
\text { Anisotropy }\end{array}$} \\
\cline { 5 - 7 } & & & & $\alpha$ & $\beta$ \\
\hline IT450100 & 434 & 24.3 & $1.6 \times 10^{21}$ & 0.64 & 0.0032 \\
\hline IT500180 & 346 & 23.3 & $1.5 \times 10^{21}$ & 0.95 & 0.010 \\
\hline IT450180 & 490 & 24.9 & $1.3 \times 10^{21}$ & 0.78 & 0.006 \\
\hline IT450200 & 286 & 42.3 & $1.0 \times 10^{21}$ & 1.16 & 0.014 \\
\hline
\end{tabular}

Table 4. Strain due to anisotropic loop density and measured total strain

\begin{tabular}{|c|c|c|c|c|}
\hline $\begin{array}{c}\text { Sample } \\
\text { Name }\end{array}$ & $\begin{array}{c}\text { Loop Anisotropy } \\
\text { Strain (\%) }\end{array}$ & $\begin{array}{c}\text { Irradiation Time } \\
(\mathrm{hr})\end{array}$ & $\begin{array}{c}\text { Measured Total } \\
\text { Strain (\%) }\end{array}$ & $\begin{array}{c}\text { Percent of Strain } \\
\text { due to Anisotropy } \\
(\%)\end{array}$ \\
\hline IT450100 & 0.006 & 170 & 0.10 & 6 \\
\hline IT450180 & 0.0056 & 80 & 0.13 & 4.3 \\
\hline IT450200 & 0.0158 & 80 & 0.36 & 4.4 \\
\hline IT500180 & 0.0067 & 30 & 0.06 & 11.2 \\
\hline
\end{tabular}


Figures:

Figure 1. Schematic of irradiation creep sample and samples used for loop orientation analysis.

Figure 2. Schematic of irradiation creep experimental facility.

Figure 3. Schematic of dislocation loop image method and geometry. The tensile direction is at an arbitrary angle to the $<001>$ image plane, and the angle between the loop normal vector to the tensile axis is defined as $\theta$.

Figure 4. TEM image of $\left.\mathrm{a}_{\mathrm{o}}<100\right\rangle$ edge-on loops with $\mathrm{g}=\langle 110\rangle$ on the $\langle 100\rangle$ zone axis. a) IT450100, b) IT450180, c)IT500180, d)IT450200.

Figure 5. Loop anisotropy plot of the irradiation creep experiments for a) IT450100, b) IT450180, c) IT500180, d) IT450200.

Figure 6. Loop anisotropy of irradiation creep experiments as a function of resolved normal stress.

Figure 7. Loop size distributions of irradiation creep samples, a) IT450100, b) IT450180, c) IT500180, d) IT450200.

Figure 8. TEM image and Kikuchi line of an $\mathrm{a}_{\mathrm{o}}<010>$ loop under two beam condition a) $\mathrm{g}=[020]$ showing outside contrast, b) $\mathrm{g}=[0-20]$ showing inside contrast.

Figure 9. TEM image and Kikuchi line of an $a_{0}<100>$ loop under two beam condition a) $\mathrm{g}=[1-10]$ showing outside contrast, $\mathrm{b}) \mathrm{g}=[-110]$ showing inside contrast.

Figure 10. Schematic of the normal vectors $n^{(k)}$ of three sets of dislocation loops, where $\mathrm{k}=$ [100], [010], and [001]. The components of the $n^{[100]}$ are defined in the Cartesian coordinate where $\mathrm{z}$-axis is the tensile axis.

Figure 11. Result of analysis of the strain due to anisotropic dislocation loops observed in samples IT450100, IT450180, IT500180, and IT450200.

Figure 12. Dislocation loop growth and interaction with the dislocation network. 


\section{Appendix: Matlab Code}

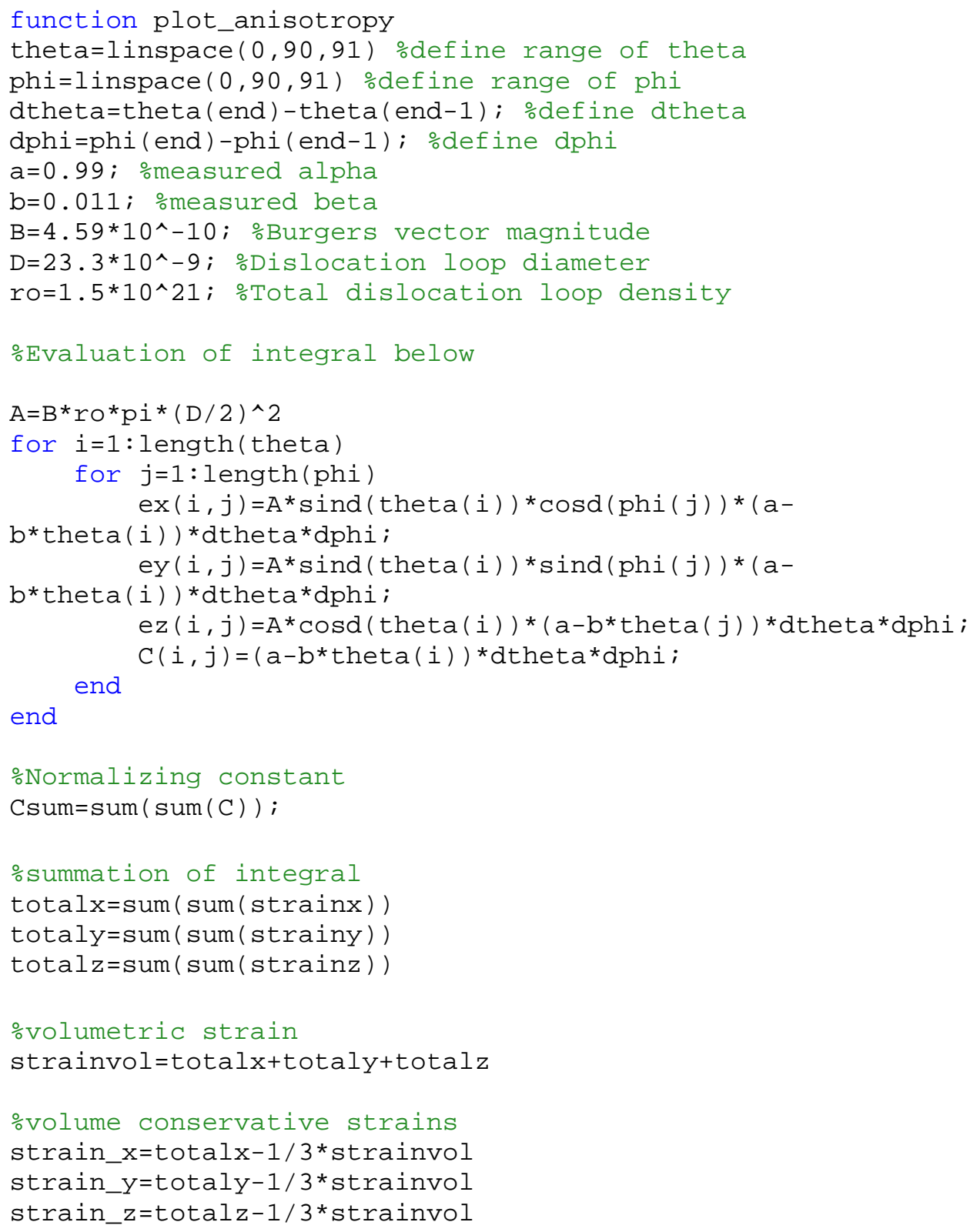




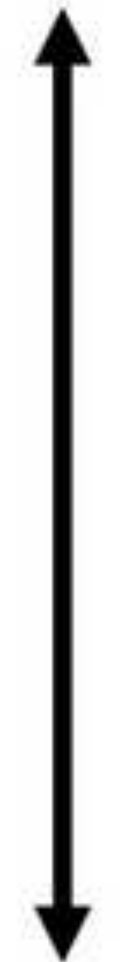

Tensile Axis
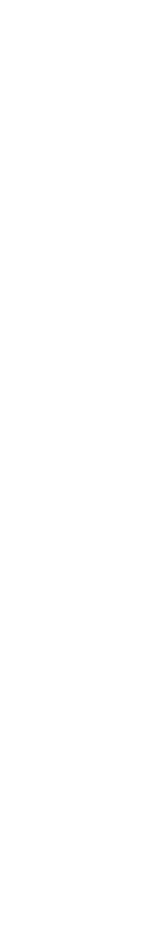

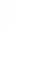$$
10 \mathrm{~mm}
$$$$
40 \mathrm{~mm}
$$

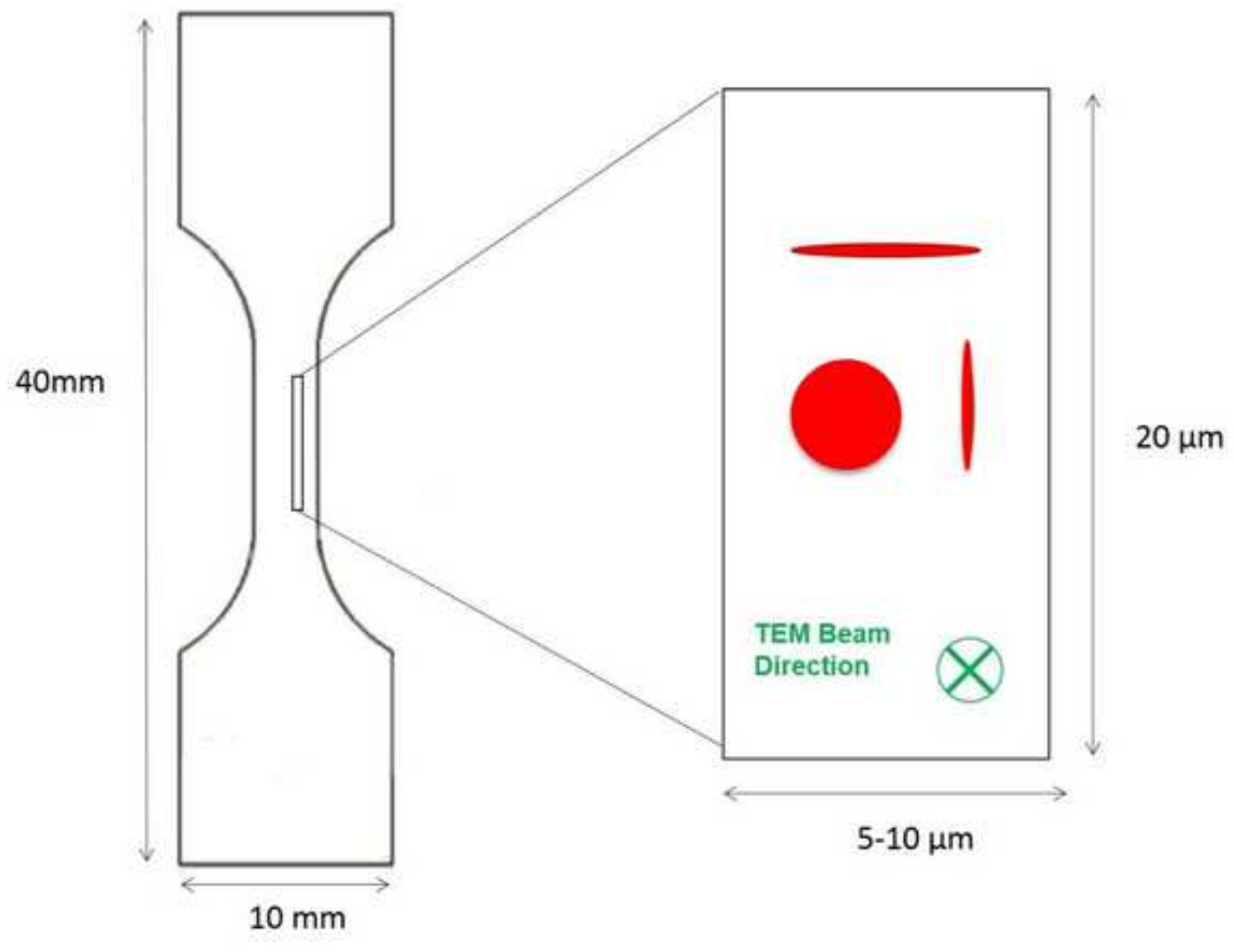

$$
\text { . }
$$

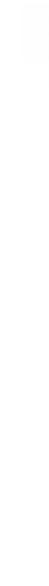




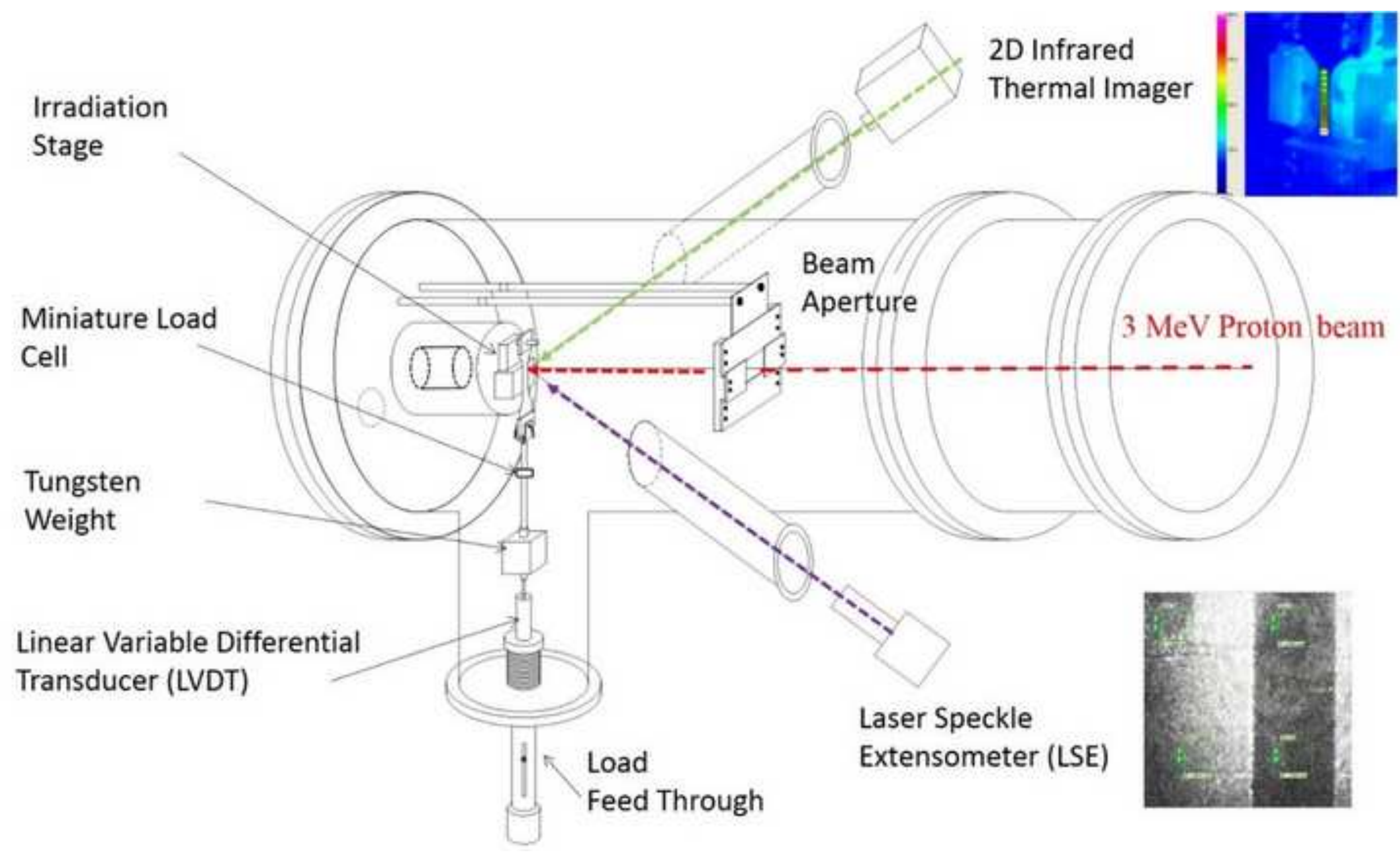




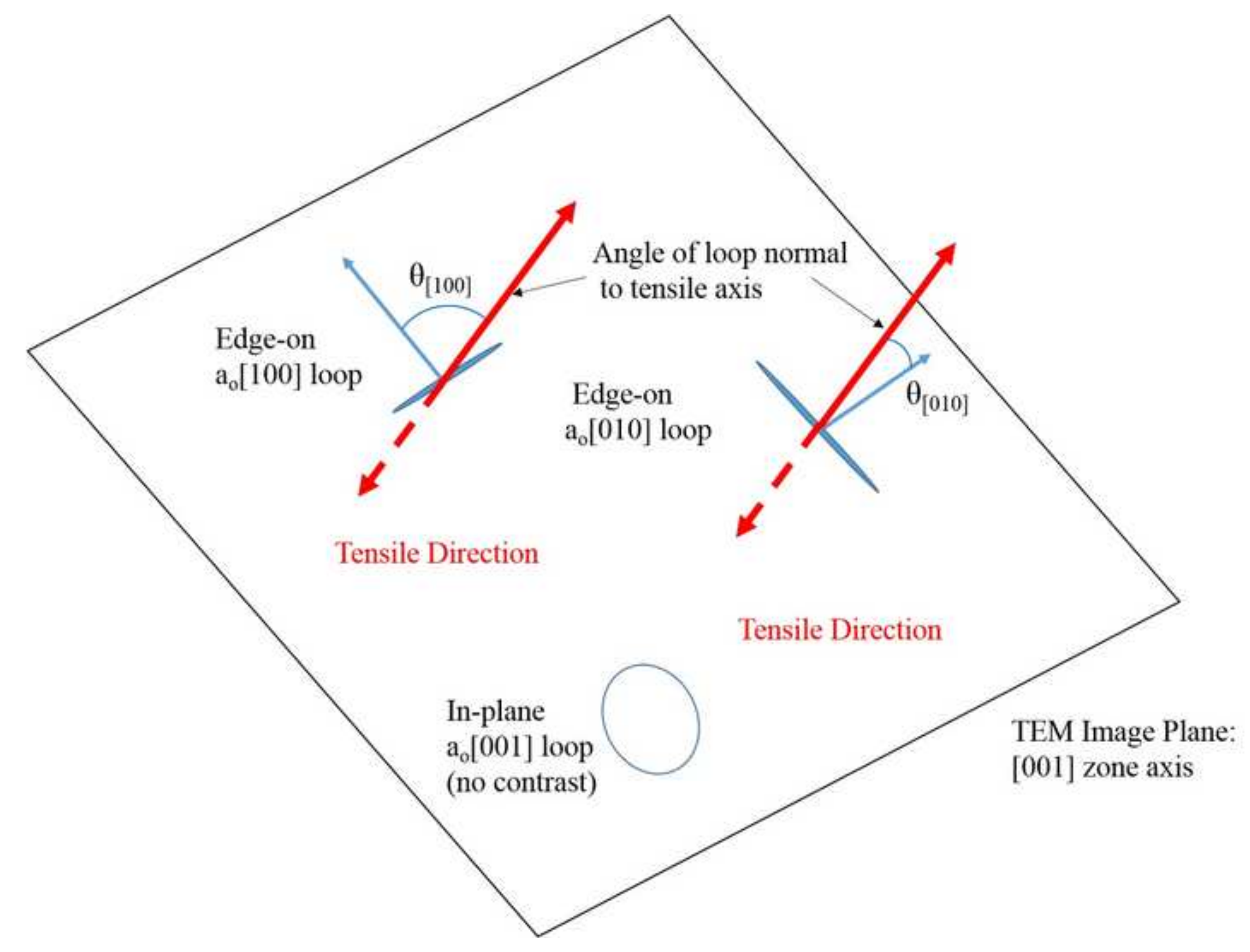




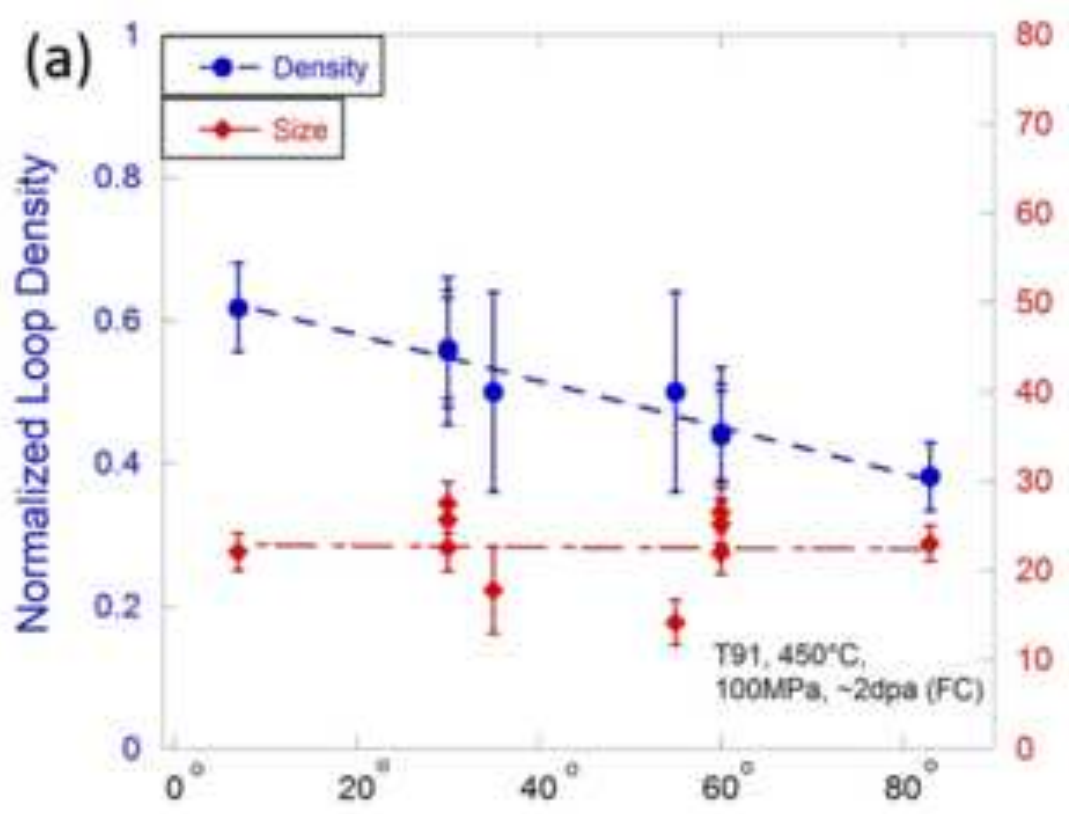

Angle Between Loop Normal and Tensile Axis

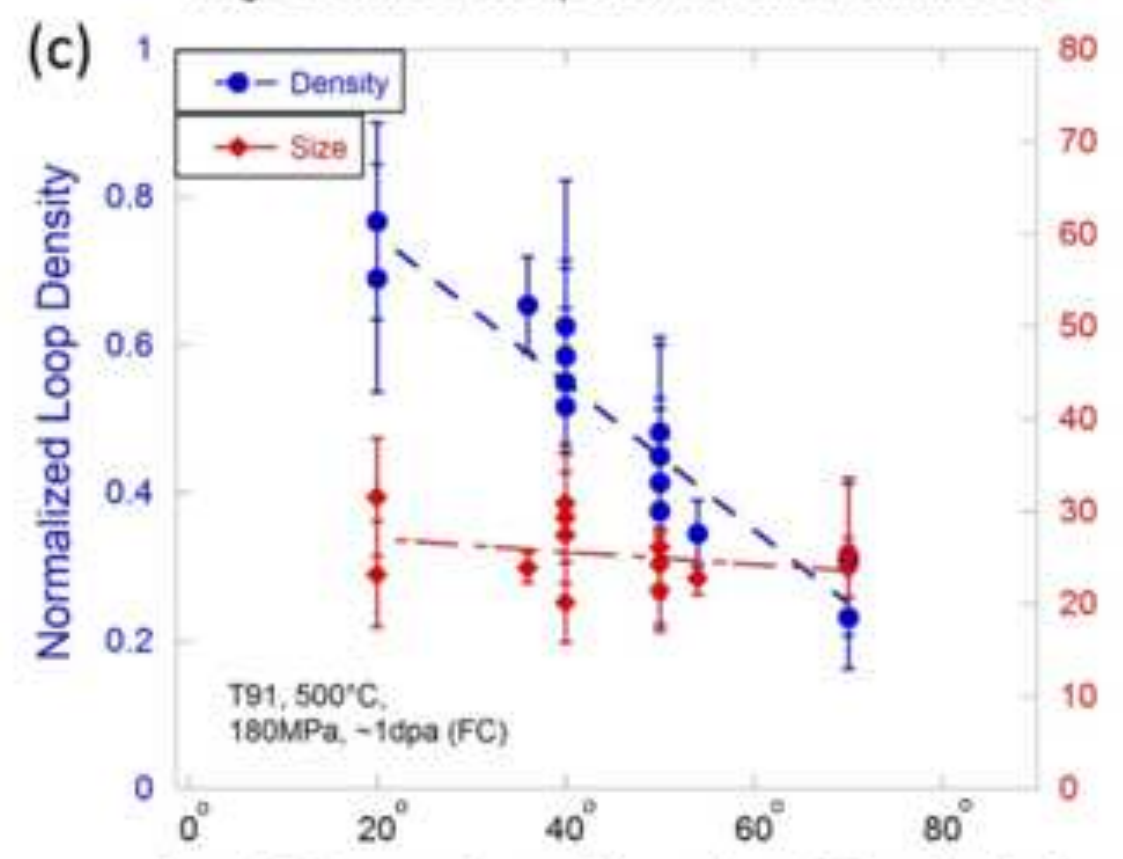

Angle Between Loop Normal and Tensile Axis

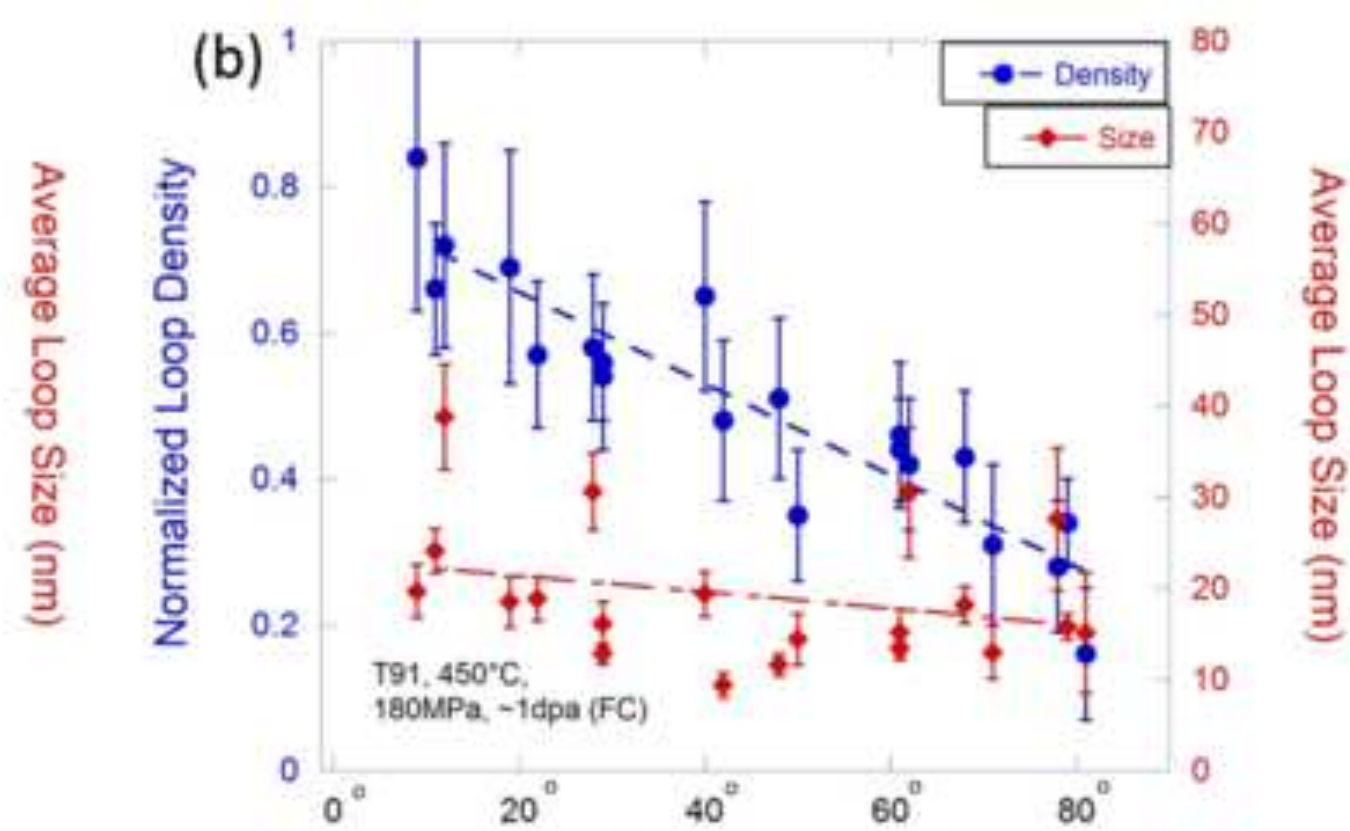

(d) Angle Between Loop Normal and Tensile Axis

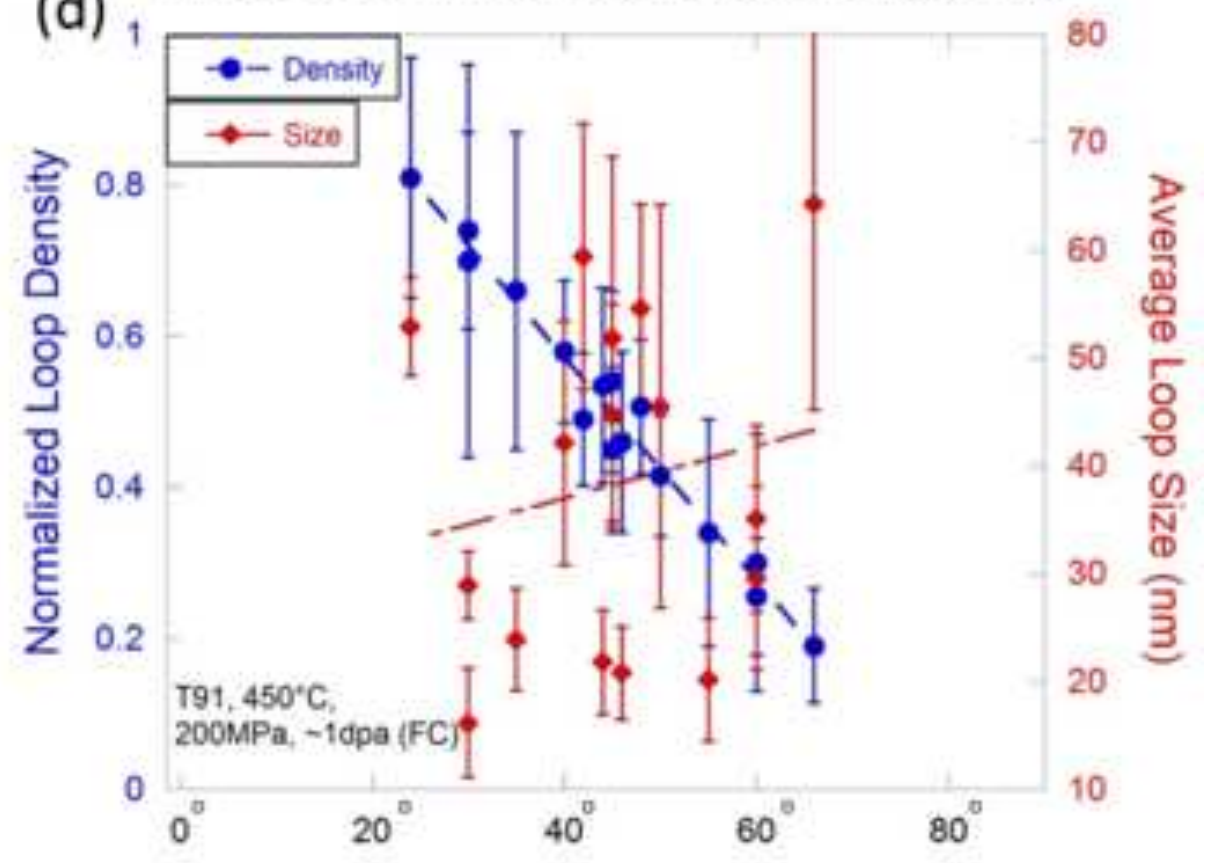

Angle Between Loop Normal and Tensile Axis 


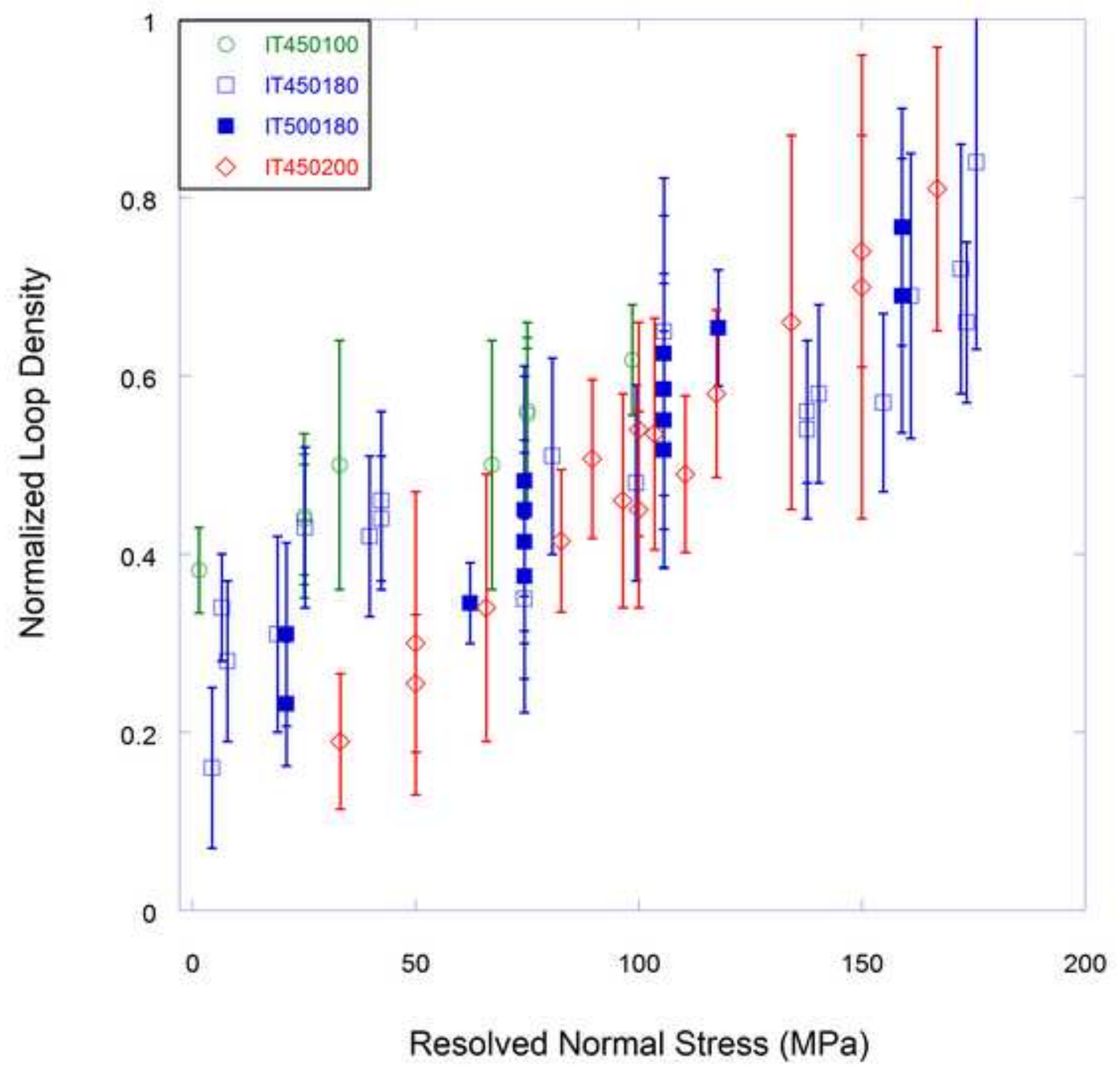



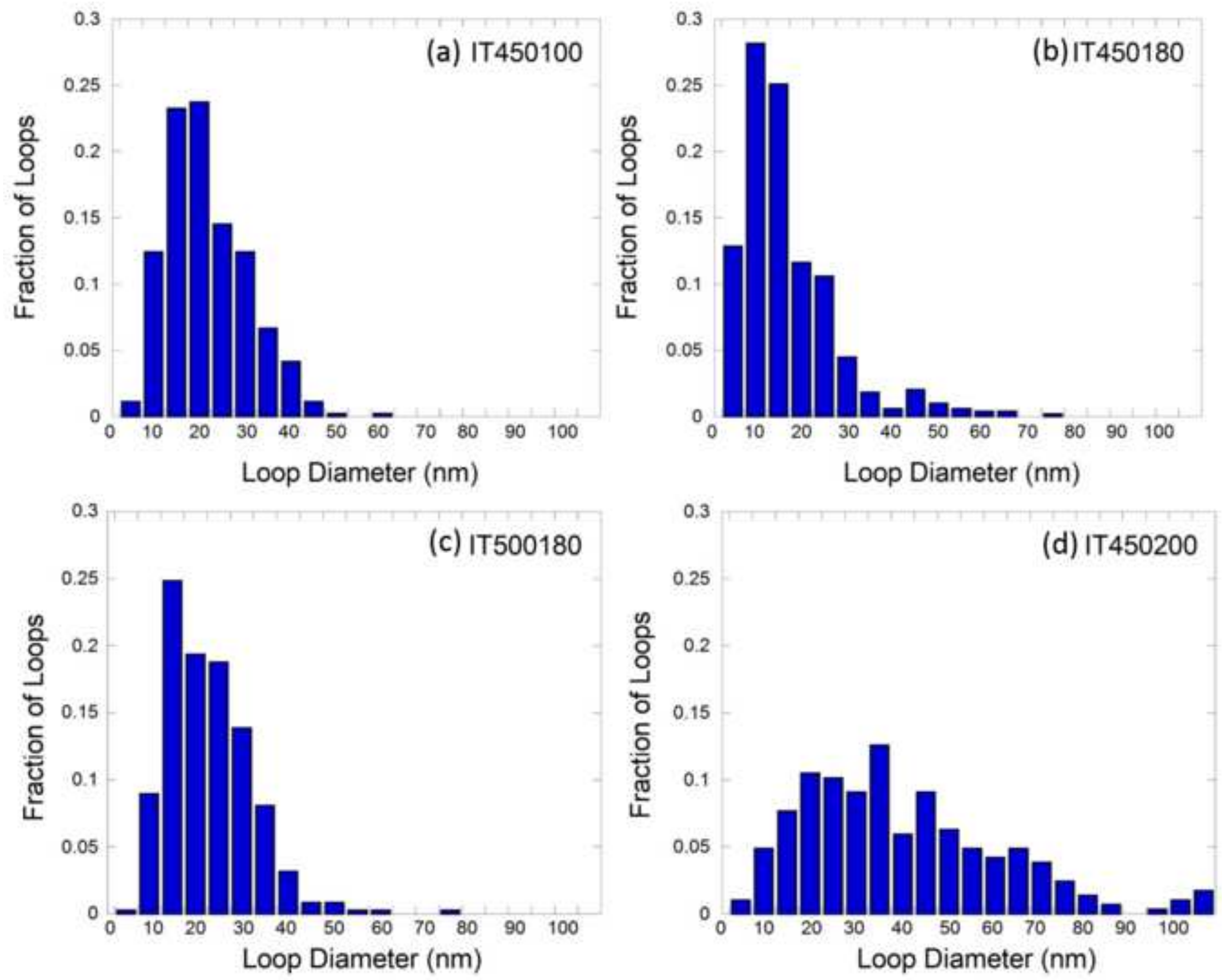


\section{(a) Outside Contrast}

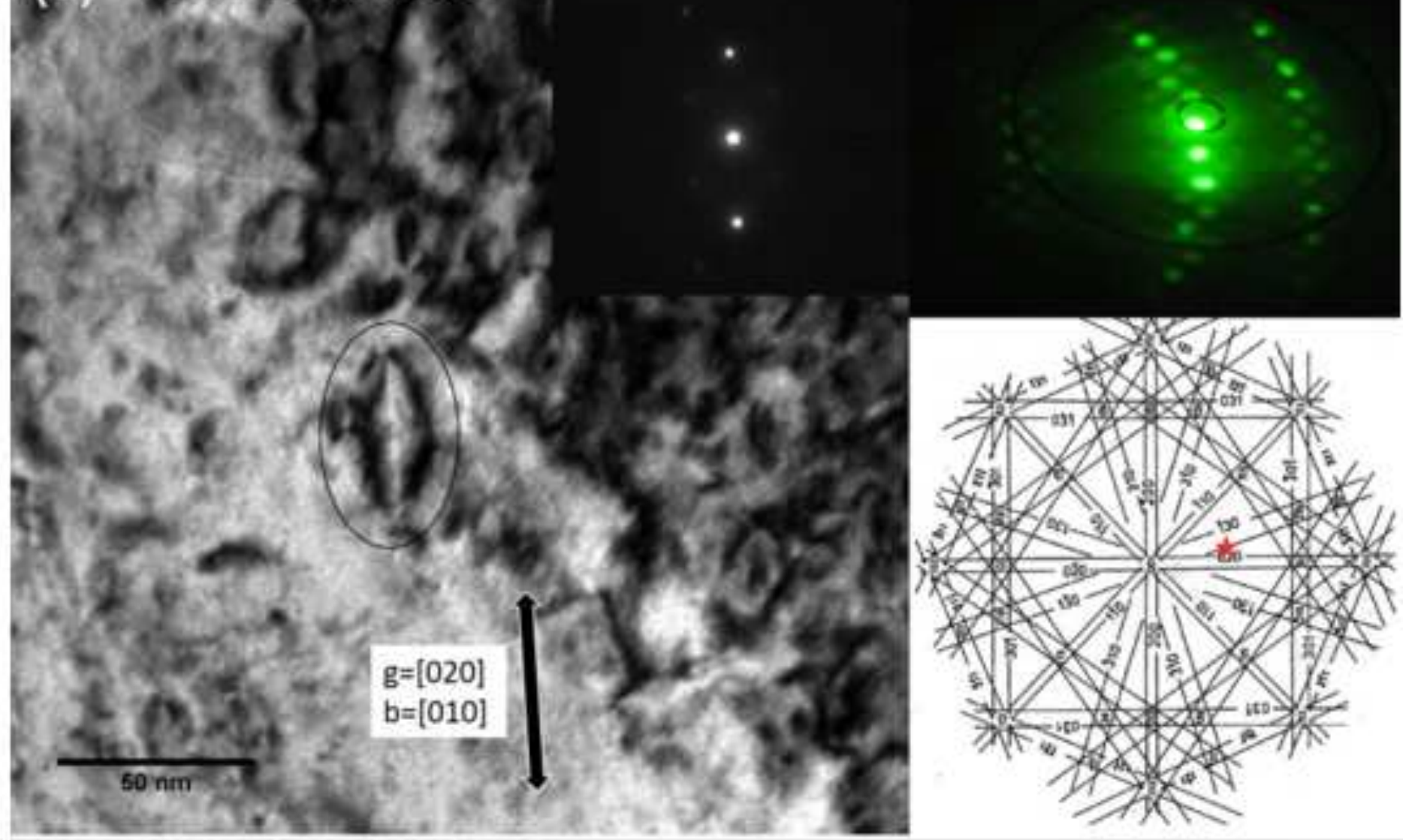

\section{(b) Inside Contrast}

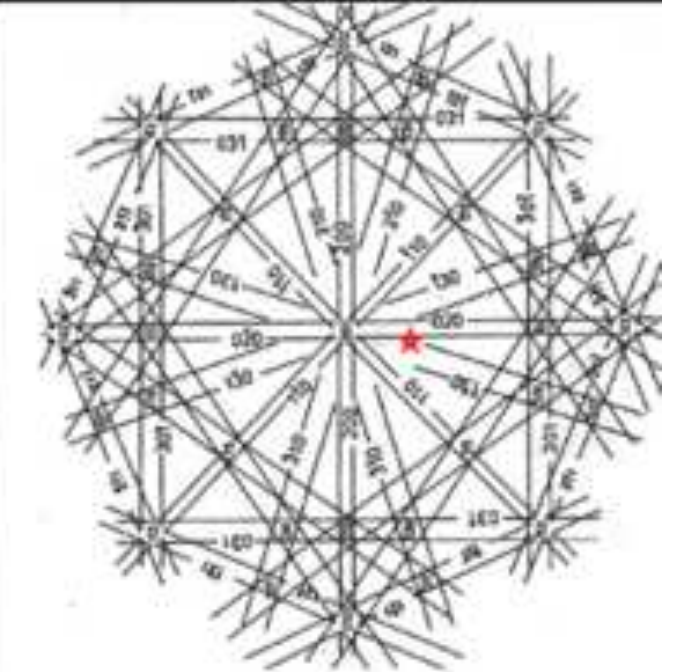




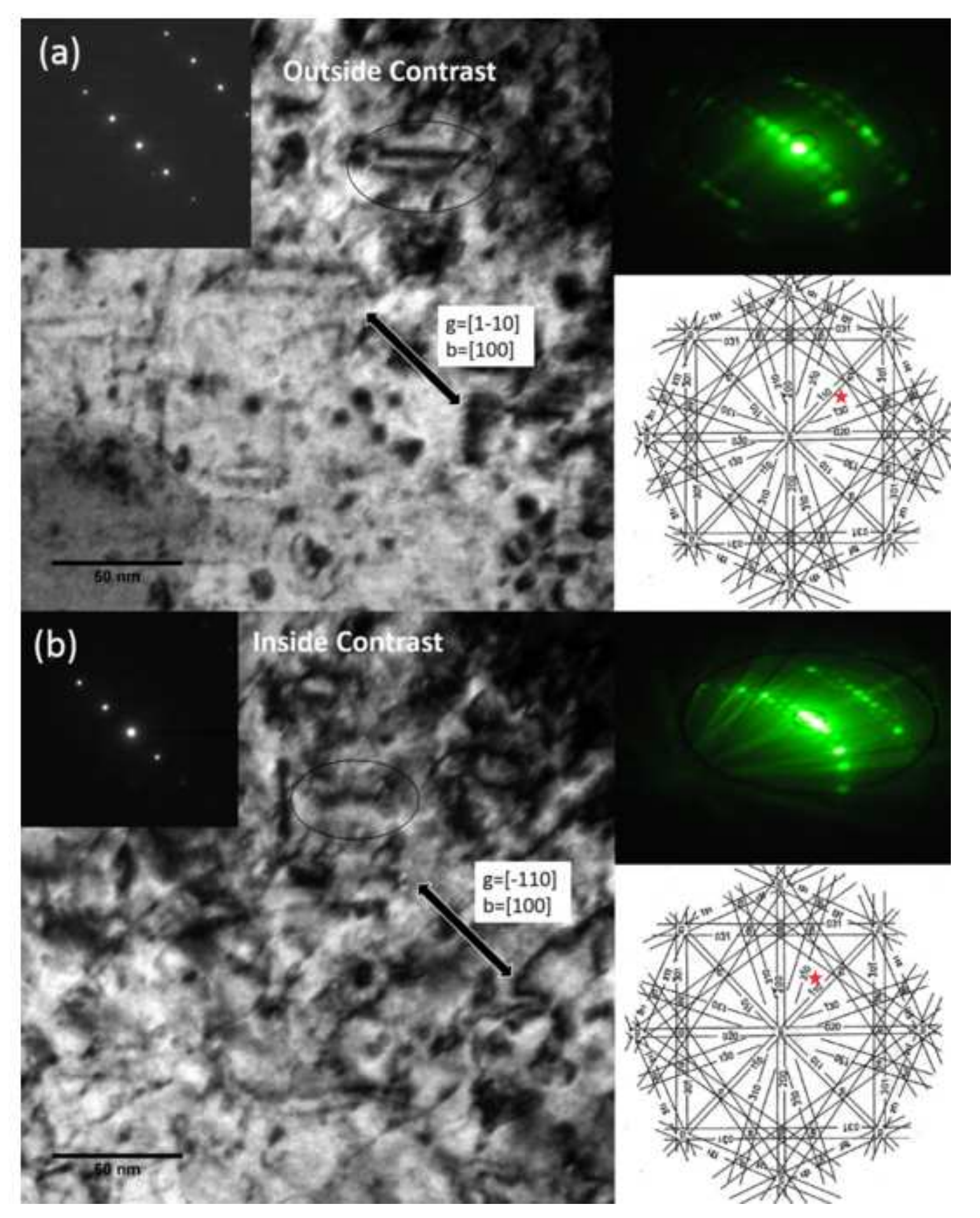

Figure
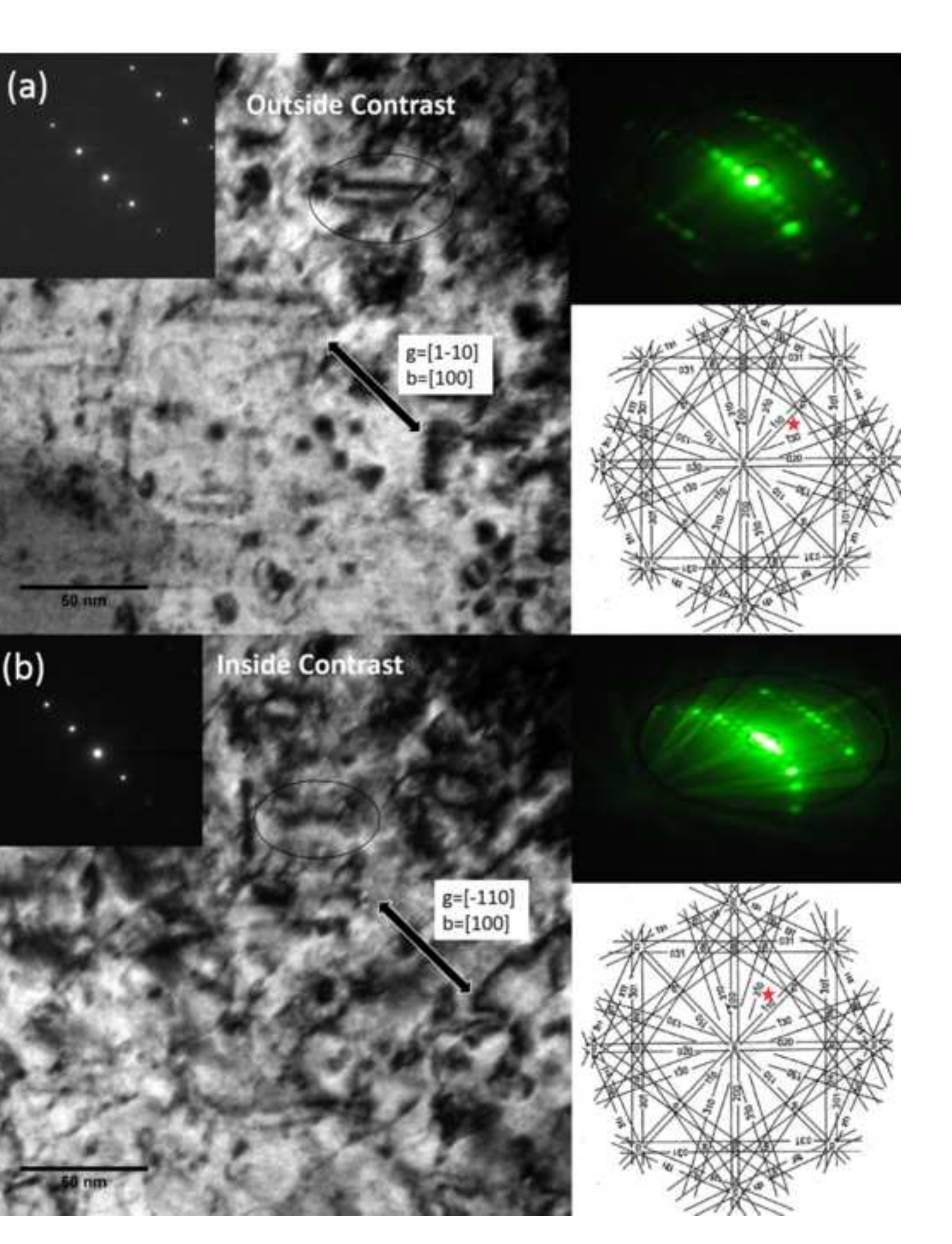


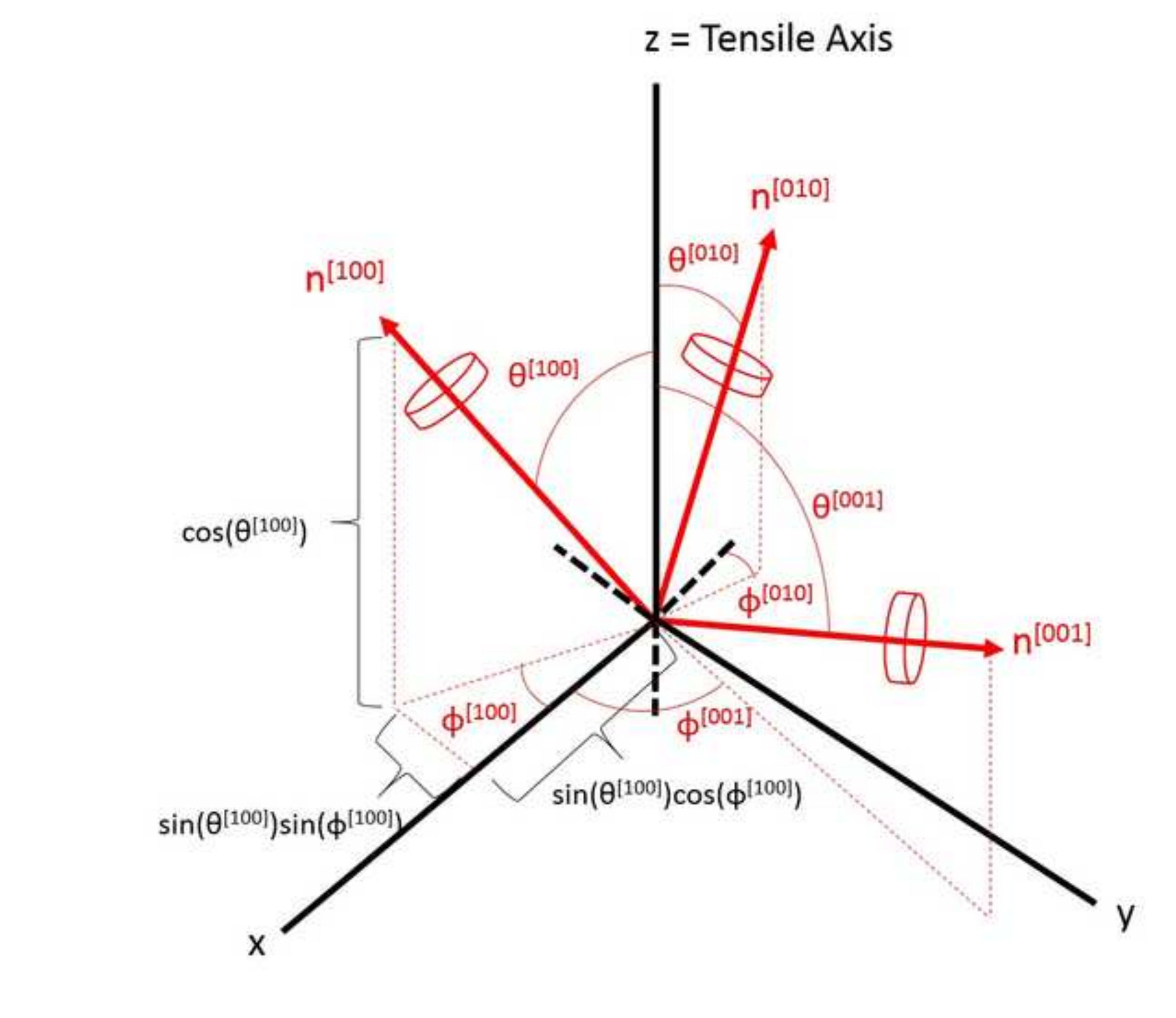

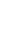

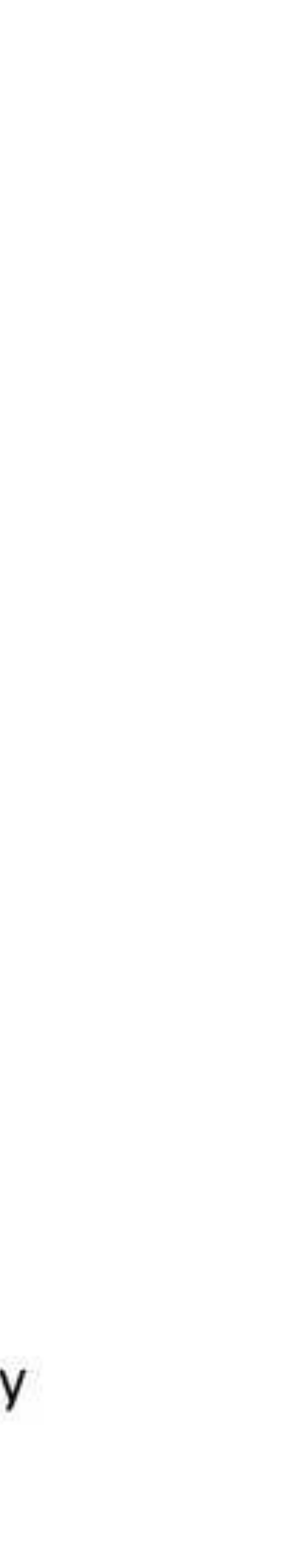

政

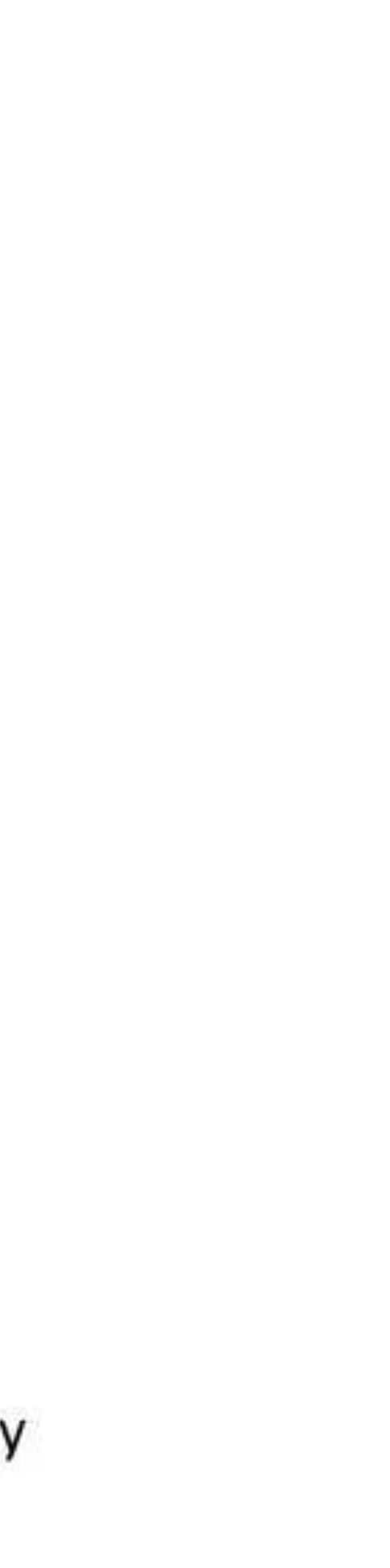

(2)
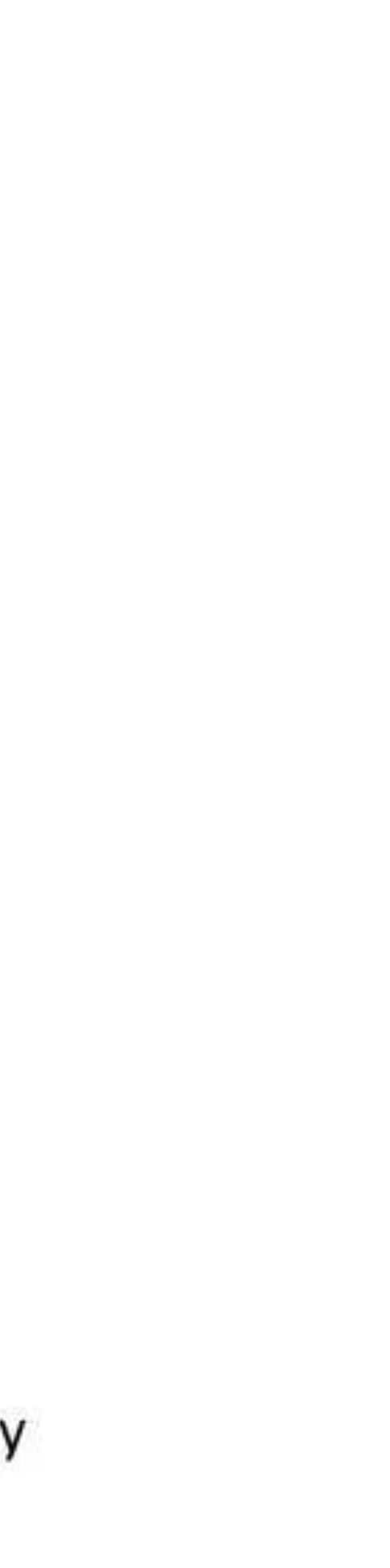

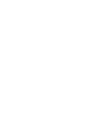

t




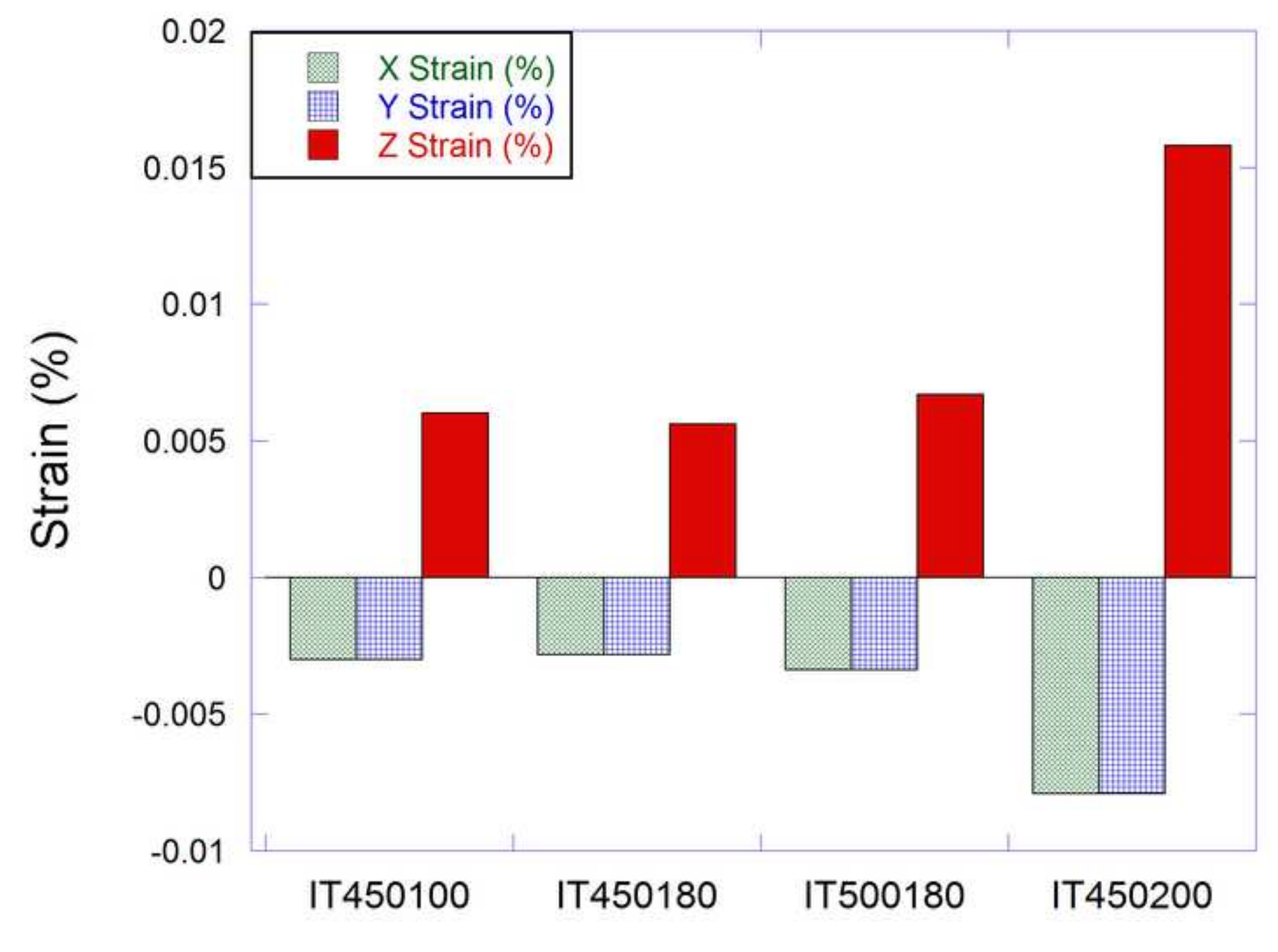

$\begin{array}{llll}\text { IT450100 } & \text { IT450180 } & \text { IT500180 } & \text { IT450200 }\end{array}$

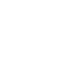

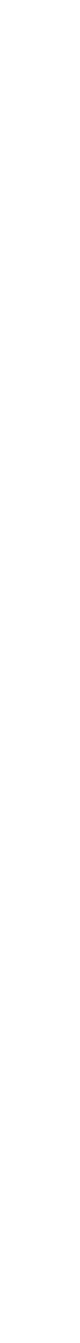

.




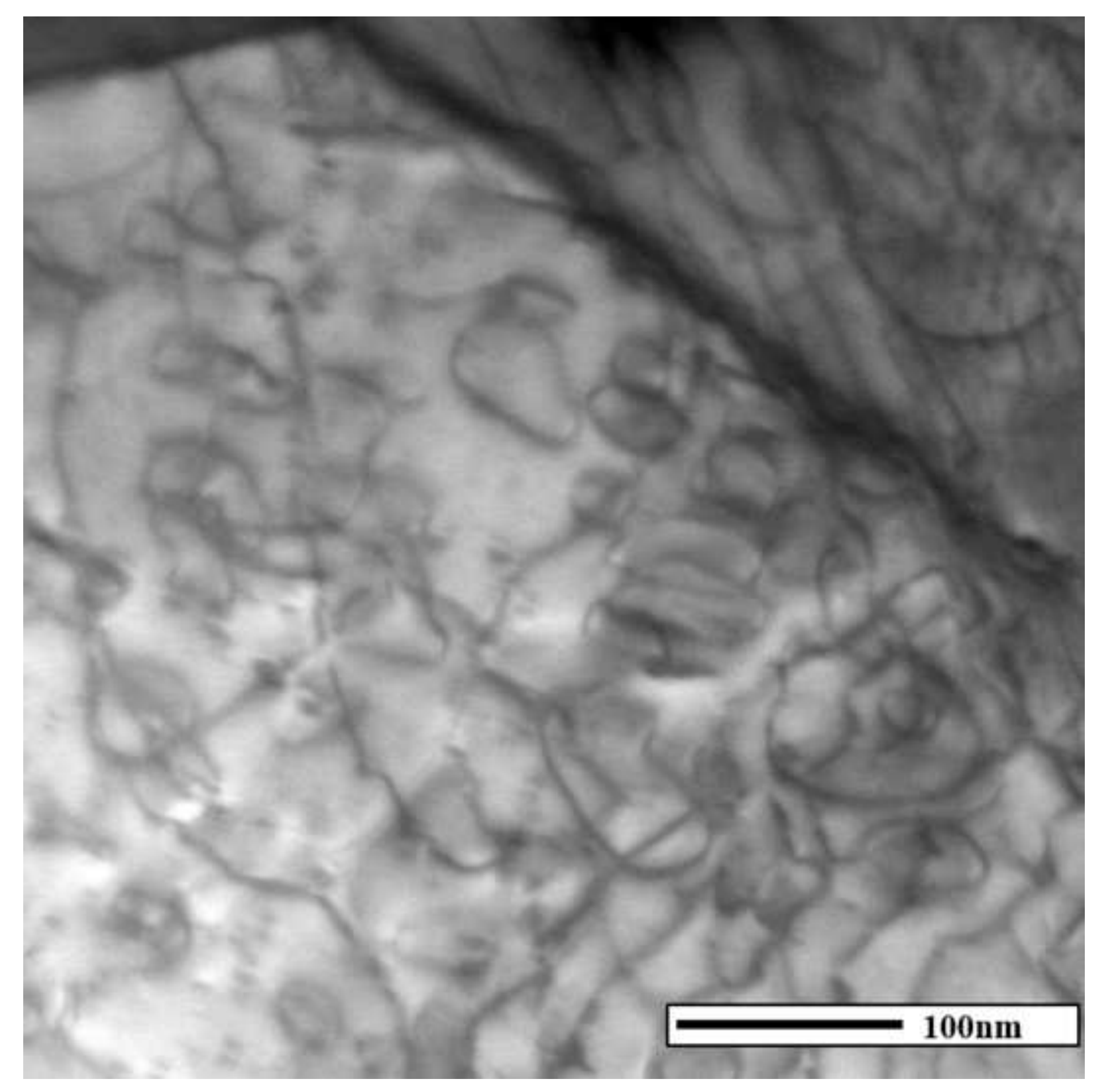

Figure 